\title{
Risk Factors of Congenital Malformations in North India: A Case-control Study
}

\author{
${ }^{1}$ Amarjeet Singh, ${ }^{2}$ Smita Sinha
}

\begin{abstract}
An increasing incidence of congenital malformations (CMF) has been reported in India.
\end{abstract}

Background and objective: To ascertain the determinants of congenital malformations.

Materials and methods: This hospital based age-sex matched pair case control study was done at Advanced Pediatric Centre, Obstetrics and Gynecology Department (ANC clinic, Maternity ward, labor room, etc.) and Special Clinics, PGIMER, Chandigarh, India in 2008. The mothers were interviewed to collect information about risk factors.

Results: Two hundred three CMF (under five children and gestational CMF) cases and same number of controls were studied. Significant association of CMF was observed with the use of sex selection drugs by mothers $(O R=4.35)$, habits of fathers like taking alcohol $(\mathrm{OR}=3)$, smoking $(\mathrm{OR}=4.5)$ and using tobacco $(O R=2.7)$. Mother's age at marriage $<18$ years and history of abortion were also important predictors of CMF.

Conclusion: Most of the risk factors for CMF were avoidable viz addiction, early marriage and use of sex selection drugs. People need to be educated about this.

Keywords: Antenatal care, Child health, Congenital malformations, Reproductive health, Sex selection.

How to cite this article: Singh A, Sinha S. Risk Factors of Congenital Malformations in North India: A Case-control Study. J Postgrad Med Edu Res 2016;50(2):59-63.

\section{Source of support: Nil}

Conflict of interest: None

\section{INTRODUCTION}

In this era of epidemiological transition communicable diseases are on the decline and a relative increase has been noted in the incidence and prevalence of noncommunicable, chronic and genetic diseases. One such group of disorders is congenital malformations (CMFs). ${ }^{1}$ Every year an estimated 8 million children $-6 \%$ of total births worldwide-are born with a serious birth defect of genetic or partially genetic origin. Additionally, hundreds

${ }^{1}$ Professor, ${ }^{2}$ Senior Resident

1,2Department of Community Medicine, Postgraduate Institute of Medical Education and Research, Chandigarh, India

Corresponding Author: Smita Sinha, Senior Resident Department of Community Medicine, Postgraduate Institute of Medical Education and Research, Chandigarh, India, Phone: +917814089771, e-mail: smita.mailid@gmail.com of thousands more are born with serious birth defects of post-conception origin due to maternal exposure to environmental agents. At least 3.3 million children less than 5 years of age die annually because of serious birth defects and the majority of those who survive are mentally and physically disabled for life. ${ }^{2}$ The reported prevalence of CMF in different studies shows a marked variability depending upon the nature of the study, inclusion of the minor defects and still birth and the period of follow-up. ${ }^{3}$ Cardiovascular malformations have been reported to be the commonest type of CMF (37\%), followed by musculoskeletal $(30 \%)$, gastrointestinal $(23 \%)$, central nervous system (13\%), and genitourinary $(6.6 \%) .{ }^{4}$

Congenital malformations have been documented to be responsible for about $15 \%$ of the perinatal mortality in India. ${ }^{5,6}$ With advancements in perinatal and neonatal care, other causes of perinatal mortality have been controlled and as in the west, the time is not far when the leading cause of perinatal mortality would be malformations. ${ }^{7}$ Congenital malformations compromise the quality of life as these affect all spheres of our activities, e.g., physical performance, competence and capability in case of major limb anomalies, central nervous system and cardiac anomalies. Congenital malformations also decrease the self image of the affected person. In some cases, it makes a person dependent on others for whole life, e.g., absence of limbs. Congenital malformations may make one dependent on drugs for lifelong, e.g., congenital thyroid disorders. ${ }^{8}$ In this context, to ensure the optimum level of health of the surviving children, it is vital that due emphasis is given to tackle the problem of CMF. As a corollary, it is essential to understand their etiological factors so that relevant prevention strategies can be planned. Against this background present study aimed to ascertain the determinants of CMF seen in PGIMER, Chandigarh, North India.

\section{MATERIALS AND METHODS}

The study was conducted at Advanced Pediatrics Centre (APC) and labor room/maternity ward/antenatal clinic/ medical termination of pregnancy (MTP) center of Department of Obstetrics and Gynecology, Postgraduate Institute of Medical Education and Research, Chandigarh. A matched pair case control design was used. The data was 
collected during May-July 2008. All cases of congenital malformation reporting at these places were registered for the study. Consecutive subjects whom the investigator was able to contact were interviewed. Consent was duly taken from the respondents. Case definition of $\mathrm{WHO}$ was used for $\mathrm{CMF}$, i.e., structural defects at birth ${ }^{9}$ and any CMF detected through ultrasound during pregnancy. ${ }^{10}$ ICD-10 classification (Code Q00-Q99) was used to categorize the cases.

For each case selected an age and sex matched control was selected from the other children attending clinics who did not have any obvious CMF. In case of prenatal detection of CMF through ultrasound, another woman of \pm 1 week of gestational age of the case was taken as control. For neonates ( $0-1$ month) a time tolerance of \pm 1 day and for children aged above 1 month up to 1 year plus or minus 15 days tolerance was allowed while selecting the controls. For example for a 6 months old male case, the control was taken from boys aged 5.5 to 6.5 months. For children above 1 year a time tolerance of 1 month was allowed when deciding about selection of controls. Mother/parents of the cases and controls were interviewed for ascertaining the determinants of CMF with the help of the study tool. Congenital malformations detected prenatally or in children less than 5 years were included in the study. Multiple pregnancy cases with mixed, anomalous and normal outcome and children above 5 years were excluded.

Matched pair analysis was used for this study. MantleHaenszel odd's ratio, 95\% confidence intervals (CIs) and $\mathrm{p}$-value for the strength of association were calculated. Univariate analysis using McNemar chi-square test with or without Yates' continuity correction was done wherever the total number of discordant pairs was at least 20. Chi-square was calculated from the discordant pairs, i.e., pairs with different status of exposure in cases and controls. Multicollinearity was considered which was absent. Then logistic regression analysis was performed. Initially, univariate logistic regression was performed to examine association of various factors with CMF. The category with no exposure was regarded as reference. For other variables without the 'no exposure' category, the group with 'least exposure' was regarded as the baseline. Respective observations with missing data were excluded, in order to maintain consistency in the univariate and multivariate analyses.

Variables identified as significant risk factors in the univariate analysis were included in logistic regression analysis. The confounding effect of age and sex were controlled by matching. Forward stepwise logistic regression using maximum likelihood ratio test was then used to test if the model would change significantly by inclusion of other factors. The level of statistical significance for univariate analysis and for the logistic model was set at 0.05 . The $p$ values for entry and removal during step wise selection were 0.05 and 0.1 , respectively.

Other variables, which were of borderline significance in the univariate analysis but were known important risk factors from the literature, were also included. Each significant and important variable was first examined to determine whether it was a confounder. This was done by examining with each of the exposures and comparing the crude and adjusted ORs. If association and a difference between crude and adjusted OR was observed, then the independent variables were considered as confounders. The confounders were tested with a forward modeling strategy, with likelihood ratio tests (LRTs) performed to assess the goodness of fit achieved by adding each variable into the model.

The order in which the variables should add into the model was indicated by the results of the crude univariate analysis. However, it has been suggested that parameter estimates obtained from a logistic regression model may be unreliable unless 10-20 events (observations) per variable are available. ${ }^{11}$ In the current study, a total of 14 parameters were estimated in the maximum logistic regression model under consideration. A best-fit model was developed in which the variables were mutually adjusted. Epi info 6 version, Statistical Package of the Social Sciences (SPSS) 17 version and (STATA) 9.0 statistical package was used for analysis.

\section{RESULTS}

Two hundred three cases and same number of controls, who were of singleton birth and age less than 5 years, were taken for study. No still birth case was recorded during the period of study. In $92 \%$ (375) children the informant was the mother. Father was the informant in $18(4.4 \%)$ children and other close relatives in $13(3.2 \%)$ children. The main source of cases was APC outpatient department (OPD) and that of controls was the healthy baby clinic or immunization center. The age of the patients ranged between " 4 months" intrauterine and " 57 months" after birth. Maximum numbers of cases were aged between 1 month to 1 year, i.e., 85 (42\%). Males out numbered the females in the ratio of 2.6:1 (Table 1). Cardiovascular malformations (Q20-28) were commonest followed by gastrointestinal (Q38-45), genitourinary (Q50-64) and central nervous system (Q00-07) (Table 2).

Matched pair analysis for risk factors is shown in the Tables 3 to 5 . 
Univariate logistic regression analysis of all the risk factors of CMF studied in the present study among matched subjects showed family history of CMF, alcohol, smoking and tobacco habituation in father, nonintake of folate by mother during the pregnancy, contraceptive use, history of abortion, history of any drug, history of

Table 1: Age and sex distribution among cases and controls $(n=190)$

\begin{tabular}{llllll}
\hline & \multicolumn{2}{c}{ Cases } & & \multicolumn{2}{c}{ Controls } \\
\cline { 2 - 3 } \cline { 6 - 6 } Age of child & $M$ & $F$ & & $M$ & $F$ \\
\hline$\leq 1$ month & 37 & 7 & & 37 & 7 \\
$>1$ month-1 year & 60 & 25 & & 60 & 25 \\
$>1-5$ years & 40 & 21 & & 40 & 21 \\
\hline Total & 137 & 53 & & 137 & 53 \\
\hline
\end{tabular}

(13 cases of CMF were detected through ultrasound in pregnant women)

Table 2: System-wise frequency of CMF $(n=203)$

\begin{tabular}{|c|c|c|c|}
\hline $\begin{array}{l}\text { Systems affected by } \\
\text { malformations }\end{array}$ & $\begin{array}{l}\text { No. of } \\
\text { cases }\end{array}$ & Percentages & ICD 10 codes \\
\hline Circulatory system & 55 & 27.1 & Q20.0-Q28.9 \\
\hline Gastrointestinal system & 47 & 23.1 & Q38.0-Q45.9 \\
\hline Central nervous system & 26 & 12.8 & Q00.0-Q07.9 \\
\hline Urinary system & 20 & 9.8 & Q60.0-Q64.9 \\
\hline Musculoskeletal system & 15 & 7.4 & Q65.0-Q79.9 \\
\hline Syndromes & 11 & 5.4 & Q80.0-Q89.9 \\
\hline Genital organs & 9 & 4.4 & Q50.0-Q56.9 \\
\hline $\begin{array}{l}\text { More than one system } \\
\text { involved but not } \\
\text { specified as syndromes }\end{array}$ & 8 & 3.9 & $\begin{array}{l}\text { More than one } \\
\text { codes for each } \\
\text { of eight cases }\end{array}$ \\
\hline $\begin{array}{l}\text { Chromosomal } \\
\text { anomalies not } \\
\text { elsewhere classified }\end{array}$ & 7 & 3.4 & Q90.0-Q90.9 \\
\hline Cleft lip, cleft palate & 3 & 1.5 & Q35.0-Q37.9 \\
\hline Respiratory system & 1 & 0.5 & Q30.0-Q34.9 \\
\hline Eye, Ear, Face, Neck & 1 & 0.5 & Q10.0-Q18.9 \\
\hline
\end{tabular}

traditional drug usage, stay near high tension tower, stay near mobile tower, age of mother at marriage $<18$ years, age of mother at first pregnancy $<20$ years as significant factors (Table 3).

Use of traditional drugs, father habituated of alcohol, no folate intake by mother, age of mother at marriage $<18$ years, history of abortion were found to be the significant risk factors by the forward stepwise approach in regression modeling (Table 5).

\section{DISCUSSION}

Birth defects are found in $2-3 \%$ of all newborns, this rate doubles in the first year and reaches $10 \%$ by the age of 5 years, as more defects become evident and can be diagnosed. Almost $20 \%$ of deaths in newborns are caused by birth defects. ${ }^{12}$

The present study could identify many potential etiological factors for CMF. In concordance with earlier observations $^{13-15}$ our study also showed association of CMF with heredofamilial factors and consanguineous marriages. There was a significant association of $\mathrm{CMF}$ with family history of CMF in our study (adjusted OR = 3).

Previous history of abortion was found to be associated significantly (adjusted OR $=1.84$ ) with $\mathrm{CMF}$. Agarwal et $\mathrm{al}^{16}$ study and Chaturvedi and Banerjee ${ }^{17}$ study also found history of previous abortion to be most significantly associated with CMF. Ronya et $\mathrm{al}^{18}$ found that higher incidence of CMF was associated with previous history of CMF.

History of threatened abortion in the present pregnancy was observed in 20 cases and 10 controls. Henry and Varma ${ }^{19}$ also showed a high positive relation between threatened abortion and major life-threatening congenital malformations.

Table 3: Risk factors with highly significant association with CMF

\begin{tabular}{|c|c|c|c|c|c|c|c|c|c|c|}
\hline \multirow[b]{2}{*}{ Risk factors } & \multirow{2}{*}{$\begin{array}{l}\text { Cases with } \\
\text { exposure } \\
(n=203)\end{array}$} & \multirow{2}{*}{$\begin{array}{l}\text { Control with } \\
\text { exposure } \\
(n=203)\end{array}$} & \multicolumn{3}{|c|}{$\begin{array}{l}\text { Exposure status of } \\
\text { case and controls }\end{array}$} & \multirow[b]{2}{*}{$D$} & \multirow{2}{*}{$\begin{array}{l}\text { Odds } \\
\text { ratio } \\
B / C\end{array}$} & \multirow{2}{*}{$\begin{array}{l}\text { Chi-square } \\
(B-C)^{2} \\
B+C\end{array}$} & \multirow{2}{*}{$\begin{array}{l}p \text {-value } \\
(d f=1)\end{array}$} & \multirow{2}{*}{$\begin{array}{l}95 \% \\
\text { confidence } \\
\text { intervals }\end{array}$} \\
\hline & & & $A$ & $B$ & $C$ & & & & & \\
\hline Family H/O CMF & 16 & 6 & 1 & 15 & 5 & 182 & 3 & 5 & 0.025 & $1.09-8.25$ \\
\hline Father alcohol & 84 & 42 & 21 & 63 & 21 & 98 & 3 & 21 & $<0.001$ & $1.83-4.9$ \\
\hline Father smoke & 48 & 16 & 7 & 41 & 9 & 146 & 4.55 & 20.48 & $<0.001$ & $2.21-9.3$ \\
\hline Father tobacco & 29 & 13 & 4 & 25 & 9 & 165 & 2.7 & 7.5 & 0.006 & $1.29-5.95$ \\
\hline Nonintake of folate & 57 & 31 & 11 & 46 & 20 & 126 & 2.3 & 10.24 & 0.0013 & $1.36-3.88$ \\
\hline Contraceptive use & 31 & 12 & 2 & 29 & 10 & 162 & 2.9 & 9.25 & 0.0023 & $1.44-6.23$ \\
\hline $\mathrm{H} / \mathrm{O}$ abortion & 163 & 141 & 115 & 48 & 26 & 14 & 1.84 & 6.54 & 0.01 & $1.14-2.97$ \\
\hline $\mathrm{H} / \mathrm{O}$ any drug & 64 & 27 & 10 & 54 & 17 & 122 & 3.17 & 19.28 & $<0.001$ & $1.84-5.47$ \\
\hline $\mathrm{H} / \mathrm{o}$ traditional drug & 83 & 26 & 9 & 74 & 17 & 103 & 4.35 & 34.46 & $<0.001$ & $2.56-7.37$ \\
\hline Stay near $\mathrm{HT}$ tower & 40 & 20 & 4 & 36 & 16 & 147 & 2.25 & 7.69 & 0.0055 & $1.24-4.05$ \\
\hline Stay near mobile tower & 60 & 40 & 13 & 44 & 27 & 116 & 1.74 & 5.40 & 0.02 & $1.08-2.79$ \\
\hline Age marriage $<18$ & 31 & 12 & 1 & 30 & 11 & 161 & 2.31 & 8.32 & 0.004 & $1.28-4.15$ \\
\hline Age of mother 1 st preg $<20$ & 42 & 20 & 5 & 37 & 16 & 145 & 2.7 & 8.8 & 0.003 & $1.36-5.44$ \\
\hline
\end{tabular}

A: Concordant pairs with both cases and controls exposed; B: Discordant pairs with case exposed and controls unexposed; C: Discordant pairs with cases not exposed and controls exposed; D: Concordant pairs with both cases and controls not exposed 
Table 4: Logistic regression model including variables chosen from those found significant in univariate analysis

\begin{tabular}{|c|c|c|c|c|c|}
\hline Risk factors & Odds ratio & Std. Err. & $z$ & $p>z$ & $95 \%$ confidence intervals \\
\hline Father smoking & 2.04 & 1.07 & 1.35 & 0.177 & $0.72-5.7$ \\
\hline Traditional drug & 3.14 & 1.01 & 3.54 & 0.000 & $1.66-5.9$ \\
\hline H/o any drug & 1.30 & 0.46 & 0.74 & 0.457 & $0.65-2.60$ \\
\hline Father alcohol & 1.84 & 0.61 & 1.83 & 0.067 & $0.96-3.53$ \\
\hline Contraceptive & 1.91 & 0.91 & 1.35 & 0.176 & $0.74-4.88$ \\
\hline No folate & 2.62 & 0.93 & 2.69 & 0.007 & $1.30-5.28$ \\
\hline Stay near HTT & 1.74 & 0.68 & 1.43 & 0.154 & $0.81-3.77$ \\
\hline Father tobacco & 1.16 & 0.66 & 0.27 & 0.786 & $0.38-3.57$ \\
\hline Age marriage $<18$ years & 1.75 & 0.65 & 1.52 & 0.129 & $0.84-3.63$ \\
\hline Age at concept $<20$ years & 4.45 & 4.64 & 1.43 & 0.152 & $0.57-34.38$ \\
\hline H/o abortion & 1.71 & 0.55 & 1.67 & 0.095 & $0.90-3.23$ \\
\hline Stay near mobile tower & 1.04 & 0.33 & 0.12 & 0.905 & $0.55-1.95$ \\
\hline Family h/o CMF & 3.25 & 2.55 & 1.50 & 0.133 & $0.69-15.18$ \\
\hline Fever in pregnancy & 3.14 & 1.75 & 2.05 & 0.041 & $1.05-9.37$ \\
\hline
\end{tabular}

Table 5: Logistic model using forward stepwise methods

\begin{tabular}{|c|c|c|c|}
\hline Risk factors & Odds ratio & Std. Err. & $\begin{array}{l}95 \% \text { confidence } \\
\text { intervals }\end{array}$ \\
\hline Traditional drug use & 3.38 & 0.98 & $1.91-6.003$ \\
\hline $\begin{array}{l}\text { Alcohol use by } \\
\text { Father }\end{array}$ & 2.25 & 0.73 & $1.45-4.48$ \\
\hline No folate intake & 2.74 & 0.91 & $1.43-5.27$ \\
\hline $\begin{array}{l}\text { Age of mother at } \\
\text { marriage }<18 \text { years }\end{array}$ & 2.30 & 0.75 & $1.22-4.36$ \\
\hline History of abortion & 1.89 & 0.57 & $1.05-3.41$ \\
\hline
\end{tabular}

Etiology of CMF is also linked to factors related to fathers. Higher odds of CMF in families where fathers were smoker $(\mathrm{OR}=4.55)$ as observed in this study might be due to passive exposure of mother to smoke. In David et $\mathrm{l}^{15}$ study also, father's cigarette smoking was more common among children with cleft lip \pm cleft palate, hydrocephalus, ventricular septal defect and urethral stenosis. Plausible mechanisms for a paternal influence on birth defects may be through genotoxic effect of smoking on the sperm. If the ovum is fertilized with a genetically altered sperm, the resulting conceptus might develop abnormally and result in a miscarriage or a live birth with malformation. ${ }^{15}$ In our study also, like David et $\mathrm{al}^{15}{ }^{15}$ we found that habituation of father to alcohol (adjusted $\mathrm{OR}=3$ ) and tobacco (adjusted $\mathrm{OR}=2.7$ ) was linked to $\mathrm{CMF}$ positively. Increased economic burden and family tension due to such addictions may also result in stressful environment in family for the pregnant women. Stress itself may act as a causal factor for CMF as also shown in many studies. ${ }^{20-23}$

In a large prospective study reported on EMF exposure in 1063 pregnant women around the San Francisco area, after participants wore a magnetic field detector, the researchers found that rates of pregnancy loss grew significantly with increasing levels of maximum magnetic field exposure in routine day-to-day life. ${ }^{24}$

A study from Shimla (North India) showed higher percentage of malformations in low maternal age group.
Agarwal ${ }^{16}$ study found the highest incidence of CMF in children born to mothers in the age group 40-44 years, whilst the lowest incidence was in the age group of 20-24 years. In our study, when maternal age at conception $<20$ years was taken in univariate logistic regression analysis it was found to be significantly associated with $\mathrm{CMF}(\mathrm{OR}=$ 5.49). This might be due to predisposition of such women for early pregnancy complications resulting from lack of proper development/maturity of reproductive tract.

Our study showed cardiovascular CMF as the commonest $(55 ; 27.1 \%)$ followed by gastrointestinal (47; $23.1 \%)$, genitourinary $(29 ; 14.2 \%)$, and central nervous system CMF $(26 ; 12.8 \%)$. Kumar et $\mathrm{al}^{4}$ also showed malformations involving cardiovascular system as the commonest $37 \%$, followed by musculoskeletal 30\%, gastrointestinal $23 \%$, central nervous system $13 \%$ and genitourinary system $6.6 \%$. In Agarwal et $\mathrm{al}^{16}$ study defects of central nervous system were the most common, accounting for almost one third (31.7\%) of all birth defects and musculoskeletal defects were equally frequent. Roy et $\mathrm{al}^{20}$ also reported that $23.7 \%$ malformed babies were affected with neural tube defects, $16.8 \%$ had cleft palate and $14 \%$ showed talipes. Ronya et $\mathrm{al}^{18}$ showed the higher incidence of gastrointestinal and genitourinary $(20.4 \%$ each) followed by central nervous system (17.3\%) CMF. Copp and Greene's ${ }^{25}$ observation of prevention of neural tube defects by folic acid was corroborated by our finding that nonintake of folic acid by mother during pregnancy was found to be significantly associated with CMF (adjusted OR $=2.3$ ). This indicates that maternal nutrition status plays a role in proper development of fetus.

History of contraceptives usage was significantly (adjusted OR $=2.9$ ) associated with CMF. But only 9 cases and two controls gave positive history of contraceptive pill intake during or just before pregnancy. Others had used barrier method mostly where the association might be due to usage of spermicidal agents. ${ }^{26,27}$ In our study, history of any drug usage during pregnancy was also found to be significantly associated with CMF (adjusted 
$\mathrm{OR}=3.17$ ). These drugs included pain killers, paracetamol, drugs for morning sickness and antibiotics.

In the present study, males outnumbered the females for CMF cases in the ratio of 2.6:1. Agarwal et $\mathrm{al}^{16}$ study on 9405 consecutive single births, male to female ratio was 1.2: 1 and in Kumar et $\mathrm{al}^{4}$ study on children between 0 and 6 years, the ratio was 1.3:1 in malformed babies. The higher representation of males in our study may be related with skewed sex ratio in Haryana and Punjab due to a high incidence of sex selective abortions in this region. ${ }^{28}$ The widely prevalent son preference also manifested in this study as the linkage of traditional sex selection drug (SSD) usage during pregnancy to have male child (especially taken during first trimester in most cases) with CMF (OR = 4.3). In Bandopadhyaya and Singh ${ }^{28}$ study also more than $90 \%$ respondents were aware of SSDs and $45.5 \%$ (40) had used SSD to have male baby. Chaung et $\mathrm{al}^{29}$ study also showed usage of traditional drug as risk factor of CMF (OR 8.62). Anecdotal reports are also available about an apparent increase in cases of CMF in North India due to use of SSDs (as reported by doctors from private nursing homes) ${ }^{28}$

\section{LIMITATIONS}

Many studies on CMF have shown linkage of CMF with environmental factors. But in hospital based studies it is difficult to establish the linkage as the surveyor may not have access to water samples to know the nitrate content in the drinking water, assess lead or methyl mercury exposure from environment, food samples, utensil samples, etc. For information on effect of these environmental factors and pollution on CMF, large scale community based studies are recommended.

Recall bias on exposure is also a limitation of case control study. Though, we tried to reduce this by including children aged less than 5 years only.

\section{REFERENCES}

1. Suresh S, Thanga VG, Sujatha J, Indrani S. Methodological issues in setting up a surveillance system for birth defects in India. Natl Med J India 2005;18(5):259-262.

2. Christianson AL, Howson CP, Modell B. White Plains New York, USA: March of dimes birth defects foundation; 2006. [Last accessed on 2011 Feb 24]. March of dimes global report on birth defects: the hidden toll of dying and disabled children. Available at: http://www.marchofdimes.com

3. Choudhery A, Talukdar G, Sharma A. Neonatal congenital malformation in Calcutta. Indian Pediatr 1984;21(5):399-405.

4. Kumar V, Singh AJ, Marwaha RK. An epidemiological study of congenital malformations in rural children. Indian Pediatr 1994;31(8):909-914.

5. Merchant SM. Annual Report, Indian Council of Medical Research Center, Mumbai 1989. p. 27.

6. Kulshreshtha $\mathrm{R}$, Nath LM, Upadhyay P. Congenital malformations in live born infants in a rural community. Indian Pediatr 1983;20(1):45-49.
7. Chaturvedi P, Banerjee KS. Spectrum of congenital malformations in newborns from rural Maharashtra. Indian J Pediatr 1989;56(4):501-507.

8. Indicators and measures of quality of life (www.bigcities. govt.nz/natural).

9. Patel ZM, Adhia RA. Birth defect surveillance study. Indian J Pediatr 2005;72(6):489-491.

10. Congenital disorder. Available at: http://en.wikipedia.org/ wiki/congenital_disorder

11. Altman DG, Royston P. What do we mean by validating a prognostic model? Stat Med 2000;19(4):453-473.

12. World health organization. Management of birth defects and haemoglobin disorders: Report of a Joint WHO-March of Dimes meeting. Geneva, Switzerland, Geneva: WHO; 2006.

13. Singh M, Jawadi MH, Arya LS, Fatima. Congenital malformations at birth among live born infants in Afghanistan: a prospective study. Indian J Pediatr 1982;49(3):331-335.

14. Pandey JA, Jarebinski M, Kastratovic B, Vlajinac H, et al. Case control study on congenital malformations. European J Epidemiol 1992;8(6):871-874.

15. David AS, Pamela JS, Martha AK. Influence of paternal age, smoking and alcohol consumption on congenital anomalies. Teratology 1991;44(4):429-440.

16. Agarwal SS, Singh U, Singh PS, Singh SS, et al. Prevalence and spectrum of congenital malformations in a prospective study at a teaching hospital. Indian J Med Res 1991 Dec;94:413-419.

17. Chaturvedi P, Banerjee KS. An epidemiological study of congenital malformations in newborn. Indian J Pediatr 1993; 60(5):645-653.

18. Ronya R, Gupta D, Ghosh SK, Narang R, Jain KB. Spectrum of congenital surgical malformations in newborns. JIMA 2002; 100(9):565-566.

19. Henry PY, Varma KK. Relationship between threatened abortion and congenital malformations. J Indian Assoc Pediatr Surg 1996;1(1):13-16.

20. Roy Choudhury A, Mukherjee M, Sharma A, Talukdar G, Ghosh PK. Study of 1,26,266 consecutive births for major congenital defects. Indian J Pediatr 1989;56(4):493-499.

21. Hansen D, Lou HC, Olsen J. Serious life events and congenital malformations: a national study with complete follow-up. Lancet 2000;356(9233):875-880.

22. Brandt LPA, Neilson CV. Job stress and adverse outcome of pregnancy: a causal link or recall bias? Am J Epidemiol 1992; 135(3):302-311.

23. Stephen JG. Fielding a current idea: exploring the public health impact of electromagnetic radiation. Public Health 2008;122(2):113-124.

24. Grover N. Congenital malformations in Shimla. Indian J Pediatr 2000;67(4):249-251.

25. Copp AJ, Greene ND. Neural tube defects: prevention by folic acid and other vitamins. Indian J Pediatr 2000;67(12):915-921.

26. Simpson JL, Phillips OP. Spermicides, hormonal contraception and congenital malformations. Adv Contracept 1990;6(3): 141-167.

27. Datta V, Chaturvedi P. Congenital malformation in rural Maharashtra. Indian J Pediatr 2000;37(9):998-1001.

28. Bandopadhyaya S, Singh AJ. Sex selection through traditional drugs in rural North India. Indian J Community Med 2007;32(1):32-34.

29. Chaung CH, Doyle P, Wang JD, Chang PJ, Lai JN, Chen PC. Herbal medicines used during the first trimesters and major congenital malformations: an analysis of data from a pregnancy cohort study. Drug Safety 2006;29(6):537-548. 